\title{
The impact of COVID-19 on digital data practices in museums and art galleries in the UK and the US
}

\author{
Lukas Noehrer (iD) ${ }^{1 凶}$, Abigail Gilmore ${ }^{1}$, Caroline Jay ${ }^{1} \&$ Yo Yehudi (i) ${ }^{1}$
}

The first quarter of 2020 heralded the beginning of an uncertain future for museums and galleries as the COVID-19 pandemic hit and the only means to stay 'open' was to turn towards the digital. In this paper, we investigate how the physical closure of museum buildings due to lockdown restrictions caused shockwaves within their digital strategies and changed their data practices potentially for good. We review the impact of COVID-19 on the museum sector, based on literature and desk research, with a focus on the implications for three museums and art galleries in the United Kingdom and the United States, and their mission, objectives, and digital data practices. We then present an analysis of ten qualitative interviews with expert witnesses working in the sector, representing different roles and types of institutions, undertaken between April and October 2020. Our research finds that digital engagement with museum content and practices around data in institutions have changed and that digital methods for organising and accessing collections for both staff and the general public have become more important. We present evidence that strategic preparedness influenced how well institutions were able to transition during closure and that metrics data became pivotal in understanding this novel situation. Increased engagement online changed traditional audience profiles, challenging museums to find ways of accommodating new forms of engagement in order to survive and thrive in the post-pandemic environment.

\footnotetext{
${ }^{1}$ The University of Manchester, Manchester, UK. ${ }_{\text {email: lukas.noehrer@manchester.ac.uk }}$
} 


\section{Introduction}

t the beginning of 2020 the COVID-19 pandemic plunged museums ${ }^{1}$ into uncharted territory. Museums around the world had to close their doors overnight, rendering their physical collections and gallery spaces inaccessible, and creating a mass exodus to the digital as the only means to stay present in their constituents' lives. This sudden rupture has prompted museums to rethink their strategies, address questions of relevance, and find ways forward that rely on virtual rather than physical interactions.

Addressing these issues required rapid planning for what was quickly termed the 'new normal' (Johnson, 2020) as suddenly the only presence was a datafied one. After a year of closure (at the time of writing), vaccination programmes and governmental determination to prevent a return to lockdown prompt the need to reflect on the implications this pandemic has for museums. The novel coronavirus has presented a new context for museum strategies and the potential for an on-demand lifestyle requires not just the rethinking of business models but possibly the reimagining of the museum in a post-pandemic world.

In this paper we investigate the impact of the pandemic on the digital data practices of public museums during 2020 and consider the implications for future digital strategies to drive and deliver museum missions and values. By digital data practices, we mean the ways digital data are used, perceived and handled within and by museums and their constituencies using digital technologies and computational methods. We explore how the pandemic has changed the ways museums provide access to public collections, consider the early and ongoing challenges they face, and the impacts these are having on organisational strategy, audience engagement, and business development. The research focuses on three museums each with publicly-owned collections, but contrasting governance and business models: Manchester Art Gallery and The National Gallery in the UK and the Smithsonian Institution in the US. Our analysis examines the mission statements, policy contexts, and digital presence of these museums, and draws on ten in-depth expert interviews with museum professionals ranging from directors to staff in digital capacities, which took place between April and October 2020. It is supported by a desk-based literature and evidence review of the impact of COVID-19 on international collecting institutions.

The first section of the article introduces a literature review which establishes the context and rationale for the research by reviewing evidence of the impact of the pandemic on museums and their digital practices. We then present the methodology for the research, which comprises an analysis of the institutional and strategic missions of the three case study museums and thematic analysis of interviews with relevant staff. We conclude with a discussion of key findings and their implications, pointing to a longer term shift in the operating models of museums and the need for further investment and innovation in digital strategies in order to realise public value.

\section{Literature review}

SARS-CoV-2 started its relentless journey across the globe in 2019 , resulting in severe restrictions on behaviour and movement in public space. By April 2020 approximately $90 \%$ of institutions (ICOM, 2020a; UNESCO, 2020) around the world were closed, putting extreme strain on the cultural sector and its constituent communities, and leading to economic and social hardship (UNESCO, 2020). As a result there was a sharp pivot towards digital technologies to facilitate the online presence of museums (Finnis and Kennedy, 2020) and provide for the increased consumption of cultural content online (Creative Industries Policy and Evidence Centre, 2020). Whilst some institutions were able to accelerate digital strategies that were already in place or make agile changes to their programming, others could not keep up with the race to provide online content (Creative Industries Policy and Evidence Centre, 2020; Art Fund, 2020). A lack of digital skills and appropriate access to training and devices (Newman et al., 2020) in the sector was laid bare by the pandemic, exacerbating persistent problems related to adopting new technologies (Merritt, 2021). Institutions were confronted with multiple challenges to their institutional infrastructures, from getting data to staff working from home, to providing digital access to audiences and monetising online assets. Rifts opened up by the pandemic exposed fundamental shortfalls in digital capacity (Knight Foundation, 2020; Newman et al., 2020) and income streams (ICOM, 2020a), as well as aggravating inequality of access and inclusion (Merritt, 2021; UNESCO, 2020).

The immediate impacts of the pandemic suggested longer term strategic and operational challenges were to come. An early survey of international museum staff (ICOM, 2020a) identified a reduction in projects and programmes in at least $80 \%$ of museums surveyed, with nearly one-third of respondents predicting they would downsize and more than one in 10 concerned they may be forced to close permanently. Whilst the survey found the majority of staff were able to work from home during lockdowns, temporary contracts were terminated or not extended, and a quarter of international freelance museum professionals reported they had not had their contracts renewed (ICOM, 2020a). A similar survey of UK museum employees reported concerns about job security and the future of their organisation (Art Fund, 2020). The situation as reported in January 2021 by the Network of European Museum Organisations found these concerns to be justified, with seven out of ten European museums expecting budget cuts over subsequent years (NEMO, 2021).

To continue operating in the context of multiple lockdowns and ongoing restrictions, museums were forced to change and/or accelerate their digital practices and processes, and many institutions, and their audiences, were thrown into the "digital deep end" (Finnis and Kennedy, 2020, p. 11), making the internet the default form of engagement. Collating museum digital initiatives during the pandemic through a crowd-sourced digital map, Zuanni (2020) found a wide variety of activities drawing on existing resources, including digitised collections and social media, and the creation of new digital content, such as virtual exhibitions, curatorial talks, and virtual tours of galleries. There was a significant rise in online content production, and republishing and repackaging content (Finnis and Kennedy, 2020), shifts which in turn necessitated changes in internal processes, such as data cleaning, cataloguing, or getting collections online (Art Fund, 2020). Those institutions with digital strategies in place reported a smoother transition than those who had previously struggled to incorporate digital products into their operations or keep pace with rapid technological developments before COVID-19 (Finnis and Kennedy, 2020; Merritt, 2021) particularly, smaller organisations with fewer resources and capacities (Travkina and Sacco, 2020). The pre-existence of organisational digital culture and capacity (Newman et al., 2020) enabled museums to bounce back faster post-COVID with "strategic foresight" (Merritt, 2021, p. 3) through the ability to "speak machine" (Maeda, 2020).

As a consequence, there has been a rapid re-assessment of the rationale for and purpose of digital engagement, placing it not as an enhancement to usual delivery or form of entertainment, but at the core of museum delivery. The presentation of museum activities via digital means has been found to provide other 
societal benefits and public services, opening up access to new resources for research and education (Agostino et al., 2020; Samaroudi et al., 2020) and providing activities which promote wellbeing and combat anxiety, mental health issues, and loneliness (Creative Industries Policy and Evidence Centre, 2020). Despite the uncertainties and huge challenges of the pandemic, there is evidence that digital strategies will have benefited considerably from renewed attention and subsequent investment. For example, ICOM's follow-up survey (2020b) conducted in November 2020 suggests further significant investment as a direct result of the sector's experience, with $75 \%$ of museums aiming to increase their digital offer and $77 \%$ planning to review their digital strategies (ICOM, 2020b, p. 18).

The increase in digital engagement and access revealed human resource issues that in many cases existed prior to COVID-19. The Knight Foundation (2020) surveyed 480 museums across the US and found that about half have either no or just one person in a digital capacity role, and just $9 \%$ of senior leadership teams (SLT) have digital experience. Similar findings are noted by Finnis and Kennedy (2020) and Merritt (2021), who identify substantial gaps in digital skills and a lack of strategic investment or positioning, with digital departments and capabilities often appearing somewhere on the organisational chart without a clear purpose or goal. Moving to digital requires a mind shift in organisational culture to address gaps in skills and knowledge, where it is not the technology itself, but rather the training and hiring of digitallyskilled staff that is the expensive part (Finnis and Kennedy, 2020).

From an audience development perspective, the shift to digitalonly participation brings the potential for new and diversified audiences to encounter museums. This is supported by UK and US surveys (The Audience Agency, 2020; Samaroudi et al., 2020), which saw a rise in engagement with less traditional and more vulnerable audiences. However, not all audiences have equal access to digital technologies and there is evidence that COVID19 has contributed to the digital divide (Holmes and Burgess, 2020), exacerbating inequalities in a society ever more reliant on data infrastructures (Baker et al., 2020). It has also had unexpected consequences in scaffolding innovation where previously old practices sufficed, rendering what Galani and Kidd (2020) discuss as "hybrid materialities" (p. 298). These deploy technological strategies that mediate between digital and analogue materials, in ways that summon imagined materialities in their remote audiences in sometimes creative and relational ways, for example, engaging new audiences who were previously unable or unwilling to physically visit museums in participatory workshops, and opening up gallery space through virtual technologies. Working outside the walls of the institution via digital and social media has provided energy to these initiatives and proof of principle in many cases, supporting educational and social missions that highlight the strategic opportunities within this strange "isolation as collective experience" (Kist, 2020, p. 346).
It is likely that the pandemic will have a long-lasting impact on the sector, prompting institutions to revisit their strategies (Samaroudi et al., 2020), address the lack of staff and digital skills training (Newman et al., 2020), and appreciate the digital as a helpful tool to re-emerge and successfully sustain over the coming years (Merritt, 2021). The notion of the future after the pandemic is noticeably different to the time before, requiring museums to embrace change and adapt to a model where "the physical space of the museum is no longer dominant" (Art Fund, 2021, p. 5). There is a new heightened interest in the monetisation of digital content, and with it the need to balance the principles of charging for content (Art Fund, 2020) with the risks of new income models and issues of accessibility and inclusion. On opening up again, museums will have to accommodate an operating environment that poses new challenges, and also offers opportunities to incorporate even-handed approaches to both onsite and digital operations which accommodate "online audiences as key agents in the production of digitally mediated material encounters" (Galani and Kidd, 2020, p. 300).

\section{Methodology}

This paper considers the experiences and responses of three museums in the United Kingdom and the United States during the first 6 months of the pandemic: the Manchester Art Gallery (MAG), the National Gallery in London, and the Smithsonian Institution based at various locations across the US. These cases were selected for their distinctiveness but also through convenience sampling as existing research partners, and are compared below in terms of their historical background, strategic missions and strategic and operational approaches to digital practice at the time of the pandemic. The design of the study was informed by the Standards for Reporting Qualitative Research (SRQR) to assure sound and rigorous data collection and reporting (O'Brien et al., 2014). The study received ethical approval by the University of Manchester Ethics Committee (Ref: 2020-9635-15157).

Ten semi-structured interviews were undertaken with professionals in each institution between April and October 2020 via the video conferencing software Zoom (Zoom Video Communications, Inc., 2020). Participants (Table 1) were purposively sampled (Mason, 2018) on the basis that they had substantial "experiential relevance" (Rudestam and Newton, 2015, p. 124) in terms of strategic and digital knowledge. Although each participant provided written consent for attribution, as we aimed to generate data that establishes a representational account of the interviewees' professional roles, we refrain from including the names of participants. All participants received a Participant Information Sheet (PIS) prior to the interview and were further given the option of withdrawing data up to 14 days after the date of participation (Noehrer et al., 2021).

\section{Table 1 Interview participants.}

\begin{tabular}{|c|c|c|c|}
\hline Participant (P) & Position & Organisation & Location \\
\hline 1 & Museum Director & MAG & UK \\
\hline 2 & Data Manager & Manchester Museum Partnership & UK \\
\hline 3 & Curator of Egypt and Sudan & Manchester Museum & UK \\
\hline 4 & Collection Information Manager & The National Gallery & UK \\
\hline 5 & Senior Manager Data and Insight & The National Gallery & UK \\
\hline 6 & Acting Director, Center for Learning and Digital Access & Smithsonian Institution & US \\
\hline 7 & Director, Digitization Programme Office & Smithsonian Institution & US \\
\hline 8 & Senior Social Science Analyst, Office of Policy and Analysis & Smithsonian Institution & US \\
\hline 9 & Associate Director of Programme Evaluation, Center for Learning and Digital Access & Smithsonian Institution & US \\
\hline 10 & Director, Smithsonian Organization and Audience Research & Smithsonian Institution & US \\
\hline
\end{tabular}


Interviews followed an interview guide (Lindlof and Taylor, 2017) based on generative questions (Rubin and Rubin, 2005) to encourage extensive replies in an open format. All interviews were transcribed in detail and cross-checked by the authors, to ensure reliability and validity (Kvale, 2007), and analysis was performed by using inductive thematic analysis (Braun and Clarke, 2006) using the software NVivo (QSR International Pty Ltd, 2020) to analyse, code and re-code the interview data, matching sentences to the primary themes in the interview $(98.2 \%, n=171)$ with an unweighted Cohen's Kappa $(\kappa=0.95)$ to reach a high level of agreement between coders (Landis and Koch, 1977).

Manchester Art Gallery. Manchester Art Gallery (MAG), a local authority owned museum operated by Manchester City Council, is part of the Manchester Museum Partnership consortium, which includes two University museums, the Manchester Museum and The Whitworth art gallery, and offers shared administrative and research capacity and a network of support and practice for its three member organisations. The main gallery is based in the centre of Manchester, with a former costume gallery and restoration centre in two branch sites in city parks. In 2019 it recorded 731,002 visitors, making it the most visited museum in the city, and also reached high numbers of people across Manchester city wards through participatory programmes (Manchester City Council, 2019a). It makes a GVA (gross value added) contribution to the local economy of $£ 13.7 \mathrm{~m}$ (Manchester City Council, 2019b).

The history of the gallery dates back to 1823 when the Royal Manchester Institution for the Promotion of Literature, Science and the Arts was founded by a group of artists, supported by local gentry and businessmen to boost the local arts market through exhibition and patronage, providing science and arts education through lecture programmes and honorary professorships (Wolff, 2013). It became the Manchester Art Gallery when it was handed to the City Corporation in 1882, with a budget to extend its collections. Dedicated as a museum for all people in Manchester, it shared similar origins, objectives and champions to its peer, the Manchester Art Museum, which was established in 1886 by Thomas Horsfall as an arts education provider for the city's working classes (Harrison, 1985).

The ambition to "diffuse useful knowledge" corresponds to the interests of the eponymous 19th century Society for the Diffusion of Useful Knowledge, which influenced the foundation of Mechanics Institutes and Lyceums and led to similar movements in the US (Portolano, 1999). MAG's current vision statement, as articulated on the gallery's webpages, reflects these historical foundations and outlines its contemporary civic and social mission to position the museum as a "'Civic Think Tank'; creating a convening space for voices across the city, providing creative education for all classes and cultures" (Manchester Art Gallery, n.d.). It also reflects the interests of the gallery's current leadership in Ruskinian theories of 'useful art', connected to the broader international 'Arte Util' network, and, as the website acknowledges, corresponds to the strategic priorities of local government (Manchester Art Gallery, n.d.) and those of key funder Arts Council England, to produce social impact through investment in arts and culture, to promote inclusion and education for the residents of Manchester, and to attract visitor economies to the city centre.

The mission of the gallery focuses on attracting and welcoming diverse audiences into the gallery spaces for the purposes of civic dialogue and education, with an emphasis on arts for health and well-being. There is little if any reference to digital or technological strategies as a means to "diffuse useful knowledge", however, and although the 'Learn' section of the gallery's website signposts engagement activities and offers curated digital content for self-guided exploration for schools and colleges, the majority of content is oriented towards encouraging visitors to enter the physical gallery spaces. There is a collections search interface which allows for simple term searches of text and images relating to over 25,000 objects, although many of these have not been digitised. Personal use of the images is permitted for browsing and viewing; for further use of more than a single copy user need to enquire via a licensing enquiry form. During lockdown there was some further content developed to allow users to access 'The Gallery at Home', including online talks and creative activities, however the emphasis remains on temporary activities which are stop-gaps for the time period of COVID restrictions, rather than new strategies to be integrated into the gallery's future.

The National Gallery. Directly grant-in-aid funded by the Department for Digital, Culture, Media and Sport (DCMS), the National Gallery in London has charitable status and is constituted as a Non-Departmental Public Body. The Gallery dates to the same year as the foundation of MAG, although its origins were ostensibly supply rather than demand-led, when in 1823 first the collector John Julius Angerstein and then landscape painter and collector Sir George Beaumont gifted their collections of paintings to the nation, necessitating a new national institution with suitable buildings for conservation and display of these collections.

The national collection now has over 2300 paintings, representing classical western traditions from the 13th to the 20th century, acquired via a mixed economy of donation, fundraising via public appeal, grant-in-aid, trusts and foundations and private donors, and primarily displayed the iconic building in Trafalgar Square. There is a discrete access policy which articulates the Gallery's commitment to "free access for all" (National Gallery, n.d.), although some temporary and special exhibitions have admissions charges and income is also generated through loans, touring exhibitions, licensing of image rights, publications, and merchandise. The Gallery has the power to raise capital via investment under the Museums and Galleries Act 1992 and maintains a carefully worded financial policy which stipulates the principles through which works of art are capitalised and appear on their balance sheet, to the concern of the Trustees, as an arbitrary valuation on their date of acquisition (HMSO, 2020), reflecting the tensions between the fluctuations of the art market, the governance of a Non-Departmental Public Body, and the need for transparency over public funds.

Following a Strategic Review of DCMS-sponsored museums (2017), the Gallery launched a new Strategic Plan that outlined significant ambitions for its business model and its use of digital technology. These included seven strategic objectives which, alongside continuation of the acquisition and conservation of major paintings, signalled an ambition to engage further within their programmes with contemporary artists and museum learning, and notably to "create a National Gallery with digital at its heart, to reflect a more digital world" (National Gallery, 2018). This pre-pandemic shift in strategy aims to embed digital technology and data capabilities across programmes to support visitor experience and audience research within the Gallery, as well as to present new opportunities for public engagement and digital display and consumption. Furthermore, digital is also noted as a key lever for the strategic objective to raise levels of self-generated income to match the Grant-in-aid and become $50 \%$ self-funded.

As the Annual Report for 2019-20 states, the pandemic has put a strain on the ambition to achieve sustained self-funding within 
the next few years. However, investment in digital capacity has furthered the Gallery's mission to provide public access to its collections, not least in supporting digital engagement during lockdown. A first stage in this was the Collections Information Project which required the complete rewriting of collection data entries, as well as investment into ticketing and customer relation management systems. New partnerships with technology and academic partners, including the Alan Turing Institute, King's College London, and Google Arts and Culture are supporting experimentation with virtual and augmented technology and an innovation lab, National Gallery X, a move which will presumably further research ambitions in technical art history as well as provide the means to take the collection out of the Gallery, and may mitigate the plans for an expanded national programme which have been curtailed by loss of funds due to the pandemic (HMSO, 2020).

The Smithsonian Institution. The bequest of James Smithson, in 1835 via his heir-less nephew, to "the United States of America, to found at Washington, under the name of the Smithsonian institution, an establishment for the increase \& diffusion of Knowledge among men (sic)" (Portolano, 1999, p. 65) led to a protracted political debate within Congress about how to interpret this vision. One group held that the institution should pursue discovery of new knowledge through the funding of empirical scientific research for the benefit and progress of society, following the Baconian philosophical traditions established by the British Royal Society popular amongst 19th century US scientists and their supporters. The other group favoured the governmental reform of public education via 'common-school' educationalism in useful arts and sciences, which echoed the moral improvement and settlement agendas found elsewhere, including in Victorian Manchester. This debate was eventually resolved through the founding of the Smithsonian Library and Museum in 1846, to exhibit and promote the products of scientific enquiry, including entire government collections of art, material sciences and natural history research. These were housed in the National Mall, maintained by resident scientists, complemented by research grants programmes and extremely popular public lectures. The latter were carefully regulated in an attempt on the part of the Organising Committee to maintain the 'neutral ground of science' and keep the Institution's knowledge diffusion free from politics, a task near impossible to achieve during the rampant partisanship of mass democratic politics in mid-19th century, civil war-torn America, until a fire put an end to the public lecture hall in 1865 (Adcock, 2014).

The Smithsonian Institution currently operates nineteen museums, eight research centres, gardens, and the National Zoo. Writing well before the advance of digitisation and digital museology, Portolano (1999) points out that by establishing a museum-dominated complex, the Smithsonian Institution retained its mission to diffuse knowledge to the common man, although it "does so primarily through the medium of exhibition of material objects" (Portolano, 1999, p. 79). Fulfilling the remit to advance scientific enquiry, digital technology and strategy now have a notably central place in the Smithsonian's mission and receive significant attention and investment. Its current strategic plan (2017-2022) identifies seven goals to achieve the vision to "build on its unique strengths to engage and to inspire more people, where they are, with greater impact, while catalysing critical conversation on issues affecting our nation and the world" (Smithsonian Institution, 2017). Two of these goals - to reach 1 billion people a year, and to drive "large, visionary, interdisciplinary research and scholarly projects"-combine to articulate the Institution's continuing commitment to increasing and diffusing knowledge, and are clearly predicated on digital technology, innovation and data science. The "digital-first strategy" is supported by a Digital Access Agenda which was incorporated into its strategic plans as early as 2014, and which emphasises technology use for enhancing visitor experience within the museums, as well as full digitization of the collections with easy, accessible, and low/no cost access to extend engagement and participation "among learners everywhere" (Smithsonian Institution, 2014). This has led to metadata, 3D objects, datasets, and a huge stock of images being released into the public domain as Creative Commons Zero (CCO) that can be used, manipulated, transformed, and shared without the need for institutional permissions (Smithsonian Institution, n.d.).

These three differently constituted institutions share in common the objectives of public education through increased access to their collections, each positioning their museums as sites for innovation, and for imparting and creating knowledge. They differ somewhat in their digital data practices and strategies, however, and in turn in their experiences and responses to the challenges of Covid-19, as we discuss in the following section.

\section{Results}

Digital practices and preparedness. As the literature review demonstrates, COVID-19 has altered the perception, use and importance of data within museums, and forced a recognition that strategic foresight and digital preparedness has significantly informed institutional ability to 'pivot' to digital delivery. This was also the case in our case study museums; although there were some different perceptions of how well things transitioned immediately after closure, all interviewees stated that COVID-19 significantly affected the way they were working. Some reported the messiness of the early days of lockdown, when operations ground to an halt, causing a situation where "everyone's just sort of fumbling around and trying to work it out, professional and organised in the lack of clarity" (P1) and that "the priorities for the whole museum have shifted to a kind of like basic needs survival mode" (P2).

Immediate response was highly reliant on the extent to which organisations had established digital data practices and infrastructure: for example, some were unable to access materials that are important to fulfil their job role either because they had no access to online systems from their homes or because physical assets, such as ledgers and artwork dossiers, had not been digitised. However, the digital preparedness of the organisations was not simply down to strategy or investment, but also lay within the grain of conventional museum practices and organisational culture. There were varying practices and approaches to the relationships between analogue and digital data, which caused barriers to digitisation. For example, in the Smithsonian Institution, analogue materials such as ledgers were the only source of metadata for collections, and it was an issue of trust to hand them over to external parties for remote digitisation, requiring a leap of faith with some refusing to lend them out (P7). At the National Gallery, a focus on providing public access to images of the artworks in the collection had dominated digitisation, with metadata, so important for research and curatorial practice, taking second place through a combined lack of resource and commitment, and remaining locked inside artwork dossiers (P4). There was criticism of a general institutional reluctance to embrace digitisation and a concern that colleagues needed a pandemic to realise that analogue material was rendered inaccessible for internal processes during lockdown, and that digitisation is as crucial to conservation as it is for reaching online audiences.

The Smithsonian Institution, in many ways the epitome of an institution that had shown strategic foresight, had adopted a "digital first strategy" within its 2017-2022 strategic plan 
(Smithsonian Institution, 2017). The pandemic consolidated and accelerated this mission:

"COVID sped up a lot of thinking that began at least two years ago when the just prior Secretary did his new strategic plan. And one of the goals was to reach 1 billion people. And you know, that would have to be virtually, would have to be digitally and moving away from the on-site visits emphasis and the emphasis on the physical buildings. And then when our new Secretary came in and one of his three major plans is the virtual Smithsonian. So, this was before any of this happened. So, the thinking was already moving in that direction." (P8)

This direction contributed to developing digital programmes on "speed drive" (P8) when COVID-19 hit the globe, allowing the Institution to repackage and purposefully reuse existing content, and ameliorating the difference in practices between its different museums, and levels of institutional reluctance:

"[We were] really fighting leadership and fighting curators and fighting other decision makers at the museum that digital should be prioritised and is important. Suddenly, everybody's like: can you make everything I'm doing digital? Can you do all my programmes? Make them all digital! So there's been a shift in sort of mindset, I think around of, you know, how we do things." (P6)

This shift in mindset was common across all three case studies and most of the interviewees reported that there was an overarching change in institutional understanding of digital data and technologies and perception of their value and significance than before the pandemic.

For MAG, "suddenly it is a sharper focus on [their] importance and role" (P2), which became the sole means for staying present to the public during lockdown, forcing institutions "to realise the capacity of data and digital in a way they didn't before" (P1), and ending the "analogue digital stand-off" (P3). As a local authority museum, with a highly localised strategy to conserve and promote collections for the city and its citizens, MAG had not yet fully embraced a digital strategy when the pandemic struck. The immediate response of the museum was to stop its operations and reflect on what digital development might mean for the gallery, rather than to spend a disproportionate amount of energy in joining museums around the world in "racing to produce endless content in an attention economy" (P1). The closure of the gallery was seen as a time to recalibrate the institution in relation to digital activities and to learn about digital content in a way "to stop seeing digital as being the signpost to a visitor experience and it being a form of collective thinking" (P1). The gallery had previously experienced how digital media had facilitated a vociferous and extensive debate about censorship and display in relation to MAG's collections, prompted by a project by the artist Sonia Boyce which included a 'gallery takeover' as part of its participatory programme (Manchester City Council, 2019a). Whilst this controversy, bruising at the time, centred on the physical removal of an artwork from display (William Waterhouse's 'Hylas and the Nymphs', leading to the social media furore being labelled Nymphgate), it left the staff aware of the potency of online audiences as well as the need to have sufficient resources to manage online dialogues. P1 remarked that institutions and people working in them will start to realise the capacity of data and the digital in a world that is going to be markedly different once opened up again, and felt that the lessons learnt after the pandemic will be reflected in the data around the collections. They argued that this could enable the use of collections in more interesting ways, referring to a complete reset of all collection data to zero "where nothing has any meaning or date and you would rebuild its meaning, connectivity, and networks or derive understanding from the network" (P1).

Developing online engagement was identified by the National Gallery as "core" (P4) to its operations. As discussed above, the National Gallery's key objective within its new corporate plan is "a National Gallery with digital at its heart, to reflect a more digital world" (National Gallery, 2018). The plan established digital as a means to fulfil a public mission for education, provide outreach of the collections, facilitate new research partnerships, and diversify income. This meant that the intention, if not the culture, for digital delivery was in place when the museum buildings closed. When asked about the perception of the physical closure, P5 stated that

"It's been really, really useful to have just one team looking at digital and physical. It helped us to really transition quite quickly to focusing on who is the digital visitor." (P5)

This was seconded by P4, who saw the impact as lessened by the fact that people were used to collaborating digitally and a working from home policy was already in place before COVID19. Outside their team, they claimed that whilst people started to realise the usefulness of putting analogue information online, they identified a tendency towards replicating established curatorial practices online rather than exploring digital data practices that would support collections management and extend engagement, such as indexing, classifying, and bringing catalogues as interoperable texts online:

"The notion of taking the sort of curatorial presentation of the collection and just doing it digitally rather than physically is probably not the best use of resources." (P4)

Whilst there was a perception of increased demand for digital content, there was uncertainty over the choice and amount of content that institutions felt they should offer in response. MAG expressed reluctance to spend what they felt was a "disproportionate amount of energy trying to provide online entertainment" (P1). Other concerns included a tendency towards "a more curator driven than user or visitor driven approach" (P8), and (also from the Smithsonian) the sense that "people just throwing digital programming out there and there is no system in place to know what's working and what isn't" (P10). The same interviewee emphasised that their pre-pandemic set-up enabled them to tailor content according to interest through user tracking and real time evaluation, delivering the content people were searching for, and avoiding users "being flooded" (P10).

The "mind shift to the digital" (P6) brought on by the pandemic was an uninvited test of the case study museums' existing commitments to digital practice as articulated within their strategic plans. For the Smithsonian Institution and the National Gallery, these afforded a level of preparedness and tools to expand and innovate digital data practices; for MAG there was more hesitation, and the immediate period of lockdown was used for reflection and to form future strategy. The next section looks at how the pandemic has impacted how data are used operationally in broader museum management processes.

Data and decision-making. Metrics and numbers have become a key trope of the pandemic: public health communications and government media briefings have been heavy with graphs, from cases and deaths to numbers of people vaccinated, in attempts to chart the progress of infections and the success or otherwise of policy interventions. This phenomenon is also observable in museum management, as senior leadership teams became significantly more metric aware and "data-driven" (P8), asking for 
metrics that either had not been tracked before, or data that was tracked but had not previously been of interest:

"One interesting thing for me is that I've gone from reporting to the Trustees once every six weeks to every week." (P5)

Data was used more directly and more often for decision making than before COVID-19, and there was a sense that data was driving decision-making in ways that might remain after the pandemic, with some wondering "whether the way we think about data as institutions will change almost in a sort of preemptive way" (P1).

As with the benefits of strategic foresight for the shift to digital delivery discussed above, the existing operational set-up and the general 'metric-awareness' of museum leadership of the case study museum influenced how they perceived and used data for performance management and to support operational reporting during the pandemic. The Smithsonian Institution's large-scale investment in user research and experience meant they already had dashboards and tracking tools to support online programming, based on analysis of content searching:

"We use user input to drive tool development [...] you know, user behaviour, that could be sort of interpreted and help us drive decision making. [...] And so we were really quickly, really specifically sort of saying: "Oh, it looks like you know, science, let's load more science into those choice boards for this next week, because that seems to be what people were looking for. [...] We were making some assumptions based on some of the data that we were seeing to drive how we're kind of packaging and presenting some material, which I think, you know, we've always kind of hoped to do in a sense." (P6)

The interviewees also reported institutional discussions and wider sector debates about the terminology of measurement, laying bare discrepancies in understanding, most notably in relation to questions of reach, engagement, and impact and how to successfully and consistently analyse and measure them. The pandemic exposed where traditional metrics were no longer fit for purpose and lacked compliance with systems for tracking new digital analytics data. For example, one participant reflected that the "challenge for data [is] to understand progress in relation to inclusion" (P2) and another that "this whole evolution toward more digital has definitely produced, you know, the need for different kinds of metrics and different kinds of data" (P8).

There were concerns about the existing skills and proficiency in using data, with one interviewee pointing out that decisions are often made under the assumption that having numbers reduces uncertainty, but in reality many decisions are based on intuition and prior knowledge, providing the contextualisation that numbers need in order to be useful (P9). Most interviewees agreed that having a data scientist or staff with skills to interpret data was essential and recognised it as a disadvantage for institutions who do not have such staff.

This new appetite for data was expanded by the management of re-openings, which was severely impacted by social distancing measures and required data to inform health and safety plans and risk assessments. The National Gallery was able to forecast and plan by using visitor tracking obtained by Wi-Fi data to predict dwell times and journeys through the gallery with graphs and machine learning models, "where tracking the most common journeys is now helping us to look at [...] what would be the best way" (P5). The application of these systems was mentioned not just regarding crowd control, but also recognised as useful to future exhibition planning, visitor management and exhibition design when placing objects in the physical museum space, for example when displaying paintings that tend to be audience magnets.

Digital audience development and engagement. Reviewing the three museums' mission statements and strategy documents it is evident that their identified audiences vary significantly in terms of reach and impact. Whereas the Smithsonian and the National Gallery define their audiences as "global" (Smithsonian Institution, 2017) and "worldwide" (National Gallery, 2018), MAG's operational reach is highly localised, as "for and of the people of Manchester" (Manchester Art Gallery, n.d.). These distinctions can also be seen in plans to extend their reach, with the Smithsonian striving to become "not only digital first, but mobile first" (Smithsonian Institution, 2017) and the National Gallery seeing digital as an "enormous opportunity" (National Gallery, 2018), whilst MAG does not make any specific reference to either online audiences or digital engagement.

Nevertheless, participants from all museums said that COVID19 sent them back to the drawing board, re-addressing questions of audience segmentation, motivation, and interaction. There were concerns that in a (post-)pandemic environment traditional visitor profiles may no longer apply and institutions may be looking at completely new and emerging audiences which sit outside of current visitor profiling. For example, the pandemic has elicited engagement with audiences beyond the classic visitor spectrum, including people who have never been to a gallery inperson before. It is important to think about the expectations of these groups when becoming first time physical visitors, foreshadowing a potentially significant change where "opening our doors, mandating how they experience the gallery" (P5) will not suffice. This concern was revealed by several participants, who remarked that most understanding of public engagement was focussed on on-site visitors, and existing data therefore cannot be used to build effective online marketing as it is still based on feedback from face to face experiences.

Participants also reported a significant increase in traffic to online portals and commented on the variety of motivations for online visiting. When asked about the most sought-after content, interviewees unequivocally said the highest demand was for educational and inspiring content, mostly driven by parents home-schooling their children and teachers (re-)using content designed for pedagogical use. There was evidence of a wider public perception of museums civic role as educators and knowledge institutions which has translated into their value during the pandemic:

"[T]hey were looking for things that were coming from a trusted source and so they didn't want just anything they could find online, they didn't necessarily want something from more of an entertainment source, they really want, they were looking for things that they assumed would have some educational value, because they were from a museum institution." (P6)

The ability to track engagement and evaluate demand helped museums to adjust content and package material according to user feedback. The malleability of digital content also provides the means for greater learner agency, for example in deciding which area to work on and when, presenting a noticeable shift in approach to curriculum facilitation and learning, since digital not only attributes agency of choice beyond classic curricula but also breaks with the often linear narratives of 'normal' museum learning in physical space, enabling a different kind of experience. Home-schooling was recognised as a driver of website traffic and also potential new museum visitors: P5 speculated how children and their parents using museum content might build confidence 
and eradicate barriers to museum engagement, having had the digital as their first touch point. This further prompted interviewees to advocate for more nuanced sets of data from audience research on reach, engagement, and accessibility in the digital realm. These were assumed to require different methodologies and analytical frames to those of on-site metrics, in order to inform inclusive programming and stop "an erasing of cultural specificity and cultural sensitivity of digital offerings" (P9). Concerns about accessibility were balanced with observations of unexpected benefits and opportunities: for example, one of the interviewees from Manchester reflected on their engagement with care home residents which would have taken a different route without the constraints of the pandemic:

"Such thoughts were provoked through experimenting with social media and digital interfaces out of the need to stay connected during lockdowns, enabling us to have discussions and conversations that may have not been possible without technology." (P3)

The Smithsonian saw an increased demand for bilingual content for parents home-schooling their children, prompting the Smithsonian's Learning Lab to develop content tailored to Spanish speakers. The Lab reported an increase in website traffic of up to $400 \%$ compared with 2019 (P6) as well as a greater demand for low-tech products, which do not require a high bandwidth or content to be printer-friendly and accessible through most devices. This prompted the Smithsonian to think of ways to reach people 'beyond device', handing out educational materials at school lunch drop-off locations where families could still come to get food even when the schools were closed, and distributing them through inserts in Amazon packaging through an innovative partnership that promoted the Institution far beyond their walls (P10).

The pandemic brought awareness of the digital divide and its impact on audience development and inclusivity to our case study museums, and also pointed to ways in which digital technologies can be used to overcome the threshold anxieties of entering the physical museum, to connect, widen reach, and produce attendance numbers that far exceed on-site events. They recognised the need to improve understanding of the impact and significance of digital museum user experience, in order to improve inclusivity and access, to blend experiences across physical and digital spaces, and to incorporate these innovations into plans for online provision post-COVID, a matter we turn to next.

Future-proofing the museum. We asked research participants to make predictions about the future of their institutions and tell us about their longer term goals. All participants agreed that the pandemic will have a long-lasting effect on their digital data practices and the ways these are used to achieve their social and strategic missions:

"This whole thing is a combination of globalisation and ecological ignorance. A many headed Hydra. And so it is more than likely that we will look at the data of our institutions in different ways as well. [...] And looking at our visitor numbers and calculating numbers of people who will be able to enter the building and justifying our existence through digital content, demographics, and data much more than we did before." (P1)

COVID-19 was seen as an opportunity to disrupt old habits and address issues that were affecting their sector, but which had not been previously at the top of the agenda. Whereas the pandemic itself was not perceived as positive, it was acknowledged that positive outcomes may come from it, and the fears most expressed were about lessons not learnt and a possible lost momentum for change:

"My sense from conversations is that people are worried about people wanting to fall back to the old normal, not realising that the only path forward-that is safe and sustainable-is going to be a new normal." (P10)

There were also concerns about resource development, sustainability and the economic impact of the pandemic on both commercial income and public funding. One of the themes that emerged was the monetisation of digital content: a theme that "they're really going to be looking at a lot" (P10). This was motivated by internal targets to increase and diversify income, particularly in the case of the National Gallery, who had already put digital at the heart of their sustainability strategy (National Gallery, n.d.). However, there was the perception that this is complicated by the difficulties in charging for cultural content, in part "because people tend to not attribute any monetary value to it" (P2), either as it seen as something already paid for through public taxation, and it therefore an existing public good, or because of an assumption that institutions should offer everything for free. This was perceived as the tension between museums on the one hand operating as revenue-driven enterprises and on the other as civic institutions whose mission is to educate and diffuse knowledge as widely as possible, already heavily subsidised by the public purse. This was notably the case for the local authority-run MAG whose operations relied on locally elected decision-making in a context of increased austerity and decimated council budgets (Manchester City Council, 2020). The lack of understanding of how to assess digital delivery in terms of measurable outcomes, performance metrics, and targets was also a perceived problem for fundraising to quantify success when attracting patrons, sponsors, and donors. There were also fears that current digital programmes cannot be sustained after re-opening the physical sites due to insufficient funds to run both at the same scale, particularly since the expectations of both the public and also leadership teams may have risen.

In addition to funding, our interviewees showed a concern about how future-proofed the sector was more broadly, in terms of longer term sustainability and leadership, with the greatest worries about smaller, less financially secure institutions and those without digital assets:

"There's a fault line between the institutions that have digitised collections and institutions who do not have digitised collections, and even actually between those who can access those collections from home and those who can't access those collections from home. And those institutions that have digitised accessible collections have been able to continue to work and continue to engage, continue to do research documentation, and those that don't have that facility are stuck and I think it's really expensive.” (P2)

The pandemic was seen as "an opportunity to really rethink everything" (P10) from streamlining operations and establishing partnerships, to including new audiences and changing business models. Its effects had put leadership teams into the unique position of steering the digital future of museums, not just in regard to their strategies, but also in terms of finding a new equilibrium between onsite and digital. There was significant concern that this opportunity would be lost due to an abiding culture of risk aversion: "[a]lthough money is always a constraint, one of the bigger constraints is the culture, the organisational culture" (P7). If this could be changed then interviewees felt a new paradigm for institutions existed that disrupted past patterns, 
using the learning from the agile responses during lockdown to integrate the progression of digital strategy and infrastructure.

\section{Discussion}

Our research finds that institutional approaches to digital and data-driven operations were a considerable factor in how well museums were prepared for a global pandemic. Attitudes towards digital data practices were significantly influenced and shaped by COVID-19, creating a new paradigm that institutions have yet to fully understand. The findings of the literature review of museum sector research reported in the first half of this paper are echoed by our case study museum interviewees, who report the experiences of their institutions' early responses to the closure of their museum spaces and the impact they had on their digital data practices. These reflect their desire to fulfil social missions established centuries before, to engage, educate and entertain audiences whilst caring for their collections, and their frustrations with imperfect digital metrics, a lack of capacity and capability in relevant skills, and a lack of foresight in digitisation which would promote new museum-visitor relationships and shore up conservation, research and curatorial processes.

Like the other surveyed museums, the case study museums reported innovation that came from digital delivery, through the 'hybrid materialities', following Gallani and Kidd (2020), which were created by technological strategies that bridge digital and analogue. These not only provided opportunities for new museum 'visitors', but also platforms through which online audiences are able to shape future strategy from beyond the institutional walls, through the tracking of their digital data showing searches and dwell times, and providing user feedback in real-time through engagement and consumption. Allied to this, there is a need for further research into specific measures which can assess the performance of digital products, to improve delivery, tailor content design and engagement practices around user experience, and to document success to satisfy and attract funders. Our analysis found that whilst financial investment in skills and capacity is important, organisational culture can be a greater barrier to digital development, with success dependent on leadership teams adopting future-facing strategies and encouraging more embedded digital cultures within their institutions.

Whilst the importance of institutional buy-in and commitment to digital strategies for future-proofing museums was a common sentiment across all case study museums, this finding was made particularly apparent by our comparative method. The three institutions shared similar founding visions and civic missions, which bely the differences in their governance histories, policy contexts and stakeholder constituencies, and in turn their approaches to digital data strategies as tools for operation and future sustainability. The strategic foresight shown by the Smithsonian and the National Gallery, who had invested significantly in digital infrastructure pre-pandemic, prepared them for a transition to remote delivery during closure, and since this infrastructure provided the means for data insights into new practices they were able to continue to innovate in facilitating engagement, for example, by creating digital products that had the potential to engage new audiences and overcome barriers of social inequality, including the digital divide. Meanwhile, whilst MAG was less able to capture the reach or impact of their own digital delivery, lacking both data and analytical capabilities, the pandemic presented the impetus, space, and focal points for reflection and learning that included recognising the unexpected benefits of participation and social practice through digital means, highlighting the importance that future digital data practices will have on their abilities to survive and thrive in the post-pandemic environment.

\section{Conclusion}

Our research finds that not only has COVID-19 impacted institutions in the short-term during lockdowns, but that it has profoundly changed the future course of museums around the globe. Whilst some museums will not be able to open their doors again, most institutions have shown great resilience and will re-emerge from this situation and adjusting their strategies and modes of operation to a new paradigm. It will be an awakening to a society that has profoundly changed too; drastic measures led to almost complete restrictions on public life, where the only means to stay connected socially and to the world beyond one's walls was a digital one.

Our research offers an in-depth account of the digital practices of three variously sized and constituted institutions during 2020 witnessed through the lens of professional practice and contextualised by a broader evidence review, which forms the basis for further research in this area. Whilst our case study range is limited to relatively well-funded public institutions based in the UK and the US, our overall findings suggest confidence in the museum sector to adapt and support further investment in the development of organisational digital culture, to ensure the sustainability of museums and their capacity to deliver social mission and public benefit on-site and online in the future.

\section{Data availability}

Data generated and analysed during the current study is not publicly available due to data sharing restrictions but is available from the corresponding author on reasonable request.

Received: 17 May 2021; Accepted: 23 September 2021; Published online: 15 October 2021

\section{Note}

1 The terms 'museum', 'art gallery', and 'institution' are used inter-changeably throughout the article.

\section{References}

Adcock R (2014) The increase and diffusion of knowledge: constructing the relation of the Smithsonian Institution to Politics, 1835-1866. Paper presented at the Annual Meeting of the American Political Science Association, Washington, DC, 28-31 August 2014. https://doi.org/10.13140/2.1.3178.5922

Agostino D, Arnaboldi M, Lema MD (2020) New development: COVID-19 as an accelerator of digital transformation in public service delivery. Public Money Manag 41(1):69-72. https://doi.org/10.1080/09540962.2020.1764206

Art Fund (2020) COVID-19 impact. Museum sector research findings. Summary report. https://www.artfund.org/assets/downloads/art-fund-covid19-researc h-report-final.pdf

Art Fund (2021) Looking ahead. Museum Sector Research May 2021. Summary report. https://www.artfund.org/assets/downloads/looking-ahead-sector-resea rch-report-2021.pdf

Baker C, Hutton G, Christie L, Wright S (2020) COVID-19 and the digital divide. UK Parliament POST, London

Braun V, Clarke V (2006) Using thematic analysis in psychology. Qual Res Psychol 3(2):77-101. https://doi.org/10.1191/1478088706qp063oa

Creative Industries Policy and Evidence Centre (2020) Digital culture: consumption in lockdown. Insights from the consumer tracking study. Thematic report. https://www.pec.ac.uk/assets/images/The-PEC-and-the-IPO-culturalconsumption-study-insights-from-the-six-week-study.pdf

DCMS (2017) Strategic review of DCMS-sponsored museums. Strategic review. https://assets.publishing.service.gov.uk/government/uploads/system/uploads/ attachment_data/file/673938/Strategic_review_of_DCMS-sponsored_muse ums.pdf

Finnis J, Kennedy A (2020) The digital transformation agenda and GLAMs. A quick scan report for Europeana. https://pro.europeana.eu/post/the-digitaltransformation-agenda-and-glams-culture24-findings-and-outcomes. Accessed 20 Feb 2021

Galani A, Kidd J (2020) Hybrid material encounters-expanding the continuum of museum materialities in the wake of a pandemic. Mus Soc 18(3):298-301. https://doi.org/10.29311/mas.v18i3.3565 
Harrison M (1985) Art and philanthropy: T.C. Horsfall and the Manchester Art Museum. In: Kidd A, Roberts K (eds.) City class and culture. Manchester University Press, Manchester, pp. 120-147

HMSO (2020) The National Gallery annual report and accounts for the year ended 31 March 2020. Annual Report. https://www.nationalgallery.org.uk/media/ 35604/the-national-gallery-annual-report-and-accounts-19-20-webversion.pdf

Holmes H, Burgess G (2020) Opinion: coronavirus has intensified the UK's digital divide. https://www.cam.ac.uk/stories/digitaldivide. Accessed 9 Apr 2021

ICOM (2020a) Museums, museum professionals and COVID-19. https:// icom.museum/wpcontent/uploads/2020/05/ReportMuseums-and-COVID19.pdf

ICOM (2020b) Museums, museum professionals and COVID-19: follow-up survey. https://icom.museum/wp-content/uploads/2020/11/FINAL-EN_Followup-survey.pdf

Johnson H (2020) Arts and culture in a 'new normal'. Psychologist 33:98-99

Kist C (2020) Museums, challenging heritage and social media during COVID-19. Mus Soc 18(3):345-348. https://doi.org/10.29311/mas.v18i3.3539

Knight Foundation (2020) Digital readiness and innovation in museums. A baseline national survey. https://knightfoundation.org/wp-content/uploads/2020/ 10/Digital-Readiness-and-Innovation-in-Museums-Report.pdf

Kvale S (2007) Doing interviews. SAGE, London

Landis JR, Koch GG (1977) The measurement of observer agreement for categorical data. Biometrics 33(1):159-174. https://doi.org/10.2307/2529310

Lindlof TR, Taylor BC (2017) Qualitative communication research methods, 7th edn. SAGE, London

Maeda J (2020) 2020 CX Report. https://cx.report/2020-cxreport/. Accessed 14 Mar 2021

Manchester Art Gallery (n.d.) Our mission and vision. https://manchesterartgallery.org/ visit/about-us/our-vision-and-mission/. Accessed 21 Apr 2021

Manchester City Council (2019a) Manchester Art Gallery Update: Manchester City Council, Report for Information Communitiesand Equalities Scrutiny Committee. 10 October 2019. https://democracy.manchester.gov.uk/ mgConvert2PDF.aspx?ID=10650\#: :text=Manchester\%20Art\%20Gallery\% 20welcomed\%20731\%2C002,museum\%20or\%20gallery\%20in\% 20ManchesterAccessed 24 Aug 2021

Manchester City Council (2019b) Manchester City Galleries' report and revenue budget 2019/20: Art Galleries Committee. 13 February 2019. https:// democracy.manchester.gov.uk/documents/s4573/Art\%20Galleries\% 20Committee\%202019.pdf Accessed 24 Aug 2021

Manchester City Council (2020) Reports Spell Out Council Budget Position. 29 October 2020. https://secure.manchester.gov.uk/news/article/8592/ reports_spell_out_councils_budget_position_-_and_options_to_address_it Accessed 25 Aug 2021

Mason J (2018) Qualitative researching, 3rd edn. SAGE, London

Merritt E (2021) TrendsWatch. Navigating a disrupted future. Report, American Alliance of Museums. https://www.aam-us.org/programs/center-for-thefuture-of-museums/trendswatch-navigating-a-disrupted-future/. Accessed 12 Mar 2021

National Gallery (2018) Strategic plan 2018-2023. https:/www.nationalgallery.org.uk/ media/25328/strategic-plan_2018-2023.pdf

National Gallery (n.d.) Access policy. https://www.nationalgallery.org.uk/about-us/ organisation/policies/access-policy. Accessed 22 Apr 2021

NEMO (2021) Follow-up survey on the impact of the COVID-19 pandemic on museums in Europe. Final Report, NEMO. https://www.nemo.org/fileadmin/ Dateien/public/NEMO_documents/NEMO_COVID19_FollowUpReport_ 11.1.2021.pdf

Newman T, Beetham H, Church, S (2020) DASH Survey Results 2020. Describing the digital attitudes, skills and organisational support of people working across the UK heritage sector. https://www.heritagefund.org.uk/sites/default/ files/media/attachments/DASH\%20report\%20draft\%20v13.1.5.pdf

Noehrer L, Gilmore A, Jay C, Yehudi Y (2021) The impact of COVID-19 on digital data practices in museums and art galleries in the UK and the US: study material. Online Resource. https://doi.org/10.48420/14604225

Noehrer, L, Jay, C, Gilmore, A, Yehudi, Y (2021) The impact of COVID-19 on digital data practices in museums and art galleries in the UK and the US: study material. University of Manchester. Online resource. https://doi.org/ 10.48420/14604225.v1

O'Brien BC, Harris IB, Beckman TJ, Reed DA, Cook DA (2014) Standards for reporting qualitative research: a synthesis of recommendations. Acad Med 89(9):1245-51. https://doi.org/10.1097/ACM.0000000000000388

Portolano M (1999) Increase and diffusion of knowledge: ethos of science and education in the Smithsonian's inception. Rhetoric Rev 18(1):65-81. https:// doi.org/10.1080/07350199909359256
QSR International Pty Ltd (2020) NVivo, version 12. Computer software. https:// www.qsrinternational.com/nvivo-qualitative-data-analysis-software/home

Rubin HJ, Rubin IS (2005) Qualitative interviewing: the art of hearing data, 2nd edn. SAGE, London

Rudestam KE, Newton RR (2015) Surviving your dissertation, 4th edn. SAGE, London

Samaroudi M, Echavarria KR, Perry L (2020) Heritage in lockdown: digital provision of memory institutions in the UK and US of America during the COVID-19 pandemic. Mus Manag Curatorsh 35(4):337-361. https://doi.org/ $10.1080 / 09647775.2020 .1810483$

Smithsonian Institution (2014) Delivering on the promise of the Digital Smithsonian. SmithsonianDigitalActionAgenda.pdf

Smithsonian Institution (2017) Strategic plan: Smithsonian 2022. https:// www.si.edu/sites/default/files/about/smithsonian-2022-strategic-plan.pdf

Smithsonian Institution (n.d.) Smithsonian Open Access. https://www.si.edu/ openaccess. Accessed 21 Jan 2021

The Audience Agency (2020) The Audience Agency digital audience survey November 2020. https://www.theaudienceagency.org/asset/2547

Travkina E, Sacco P (2020) Culture shock: COVID-19 and the cultural and creative sectors. Tackling Coronavirus (COVID-19): contributing to a Global Effort. OECD, Paris

UNESCO (2020) Museums around the world in the face of COVID-19. Report. https://unesdoc.unesco.org/ark:/48223/pf0000373530. Accessed 27 Oct 2021

Wolff J (2013) Calico connections: science, manufacture and culture in midnineteenth-century Manchester. In: Wolff J, Savage M (eds) Culture in Manchester Institutions and urban change since 1850. Manchester University Press, Manchester

Zoom Video Communications, Inc. (2020) ZOOM cloud meetings, Version 5. Computer software. https://zoom.us.

Zuanni C (2020) Mapping museum digital initiatives during COVID-19. https:// pro.europeana.eu/post/mapping-museum-digital-initiatives-during-covid-19. Accessed 13 Aug 2021

\section{Acknowledgements}

This work was supported by the UK Engineering and Physical Sciences Research Council (EPSRC) grant EP/R513131/1 for the University of Manchester and we further acknowledge funding for Gilmore from AHRC/UKRI COVID-19: Impacts on the Cultural Industries and Implications for Policy (AH/V00994X/1) and AHRC Centre of Excellence for Policy and Evidence in the Creative Industries (AH/S001298/ 1). We would also like to thank our participants for their time in participating in this study.

\section{Competing interests}

The authors declare no competing interests.

\section{Additional information}

Correspondence and requests for materials should be addressed to Lukas Noehrer.

Reprints and permission information is available at http://www.nature.com/reprints

Publisher's note Springer Nature remains neutral with regard to jurisdictional claims in published maps and institutional affiliations.

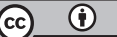

Open Access This article is licensed under a Creative Commons Attribution 4.0 International License, which permits use, sharing, adaptation, distribution and reproduction in any medium or format, as long as you give appropriate credit to the original author(s) and the source, provide a link to the Creative Commons license, and indicate if changes were made. The images or other third party material in this article are included in the article's Creative Commons license, unless indicated otherwise in a credit line to the material. If material is not included in the article's Creative Commons license and your intended use is not permitted by statutory regulation or exceeds the permitted use, you will need to obtain permission directly from the copyright holder. To view a copy of this license, visit http://creativecommons.org/ licenses/by/4.0/.

(C) The Author(s) 2021 